\title{
Gas and RRR distribution in high purity Niobium EB welded in Ultra-High Vacuum.
}

\author{
S. Anakhov (RSVPU, Yekaterinburg - Russia) \\ X. Singer, W. Singer (DESY, Hamburg - Germany) \\ H. Wen (IEE CAS, Beijing - China)
}

Electron beam (EB) welding in UHV (ultra-high vacuum, $10^{-5} \div 10^{-8}$ mbar) is applied in the standard fabrication of high gradient niobium superconducting radio frequency (SRF) cavities of TESLA design. The quality of EB welding is critical for cavity performance. Experimental data of gas content $\left(\mathrm{H}_{2}, \mathrm{O}_{2}, \mathrm{~N}_{2}\right)$ and $\mathrm{RRR}$ (residual resistivity ratio) measurements in niobium $(\mathrm{Nb})$ welding seams are presented. $\mathrm{EB}$ welding in UHV conditions allow to preserve low gas content $(1 \div 3 \mathrm{wt}$. ppm hydrogen and $5 \div 7 \mathrm{ppm}$ oxygen and nitrogen), essential for high values of RRR $350 \div 400$ units. Gas content redistribution in the electron beam welded and heat affected region take place in the welding process. Correlation between gas solubility parameters, RRR and thermal conductivity are presented. Mechanisms of gas solubility in EB welding process are discussed.

\section{Introduction.}

The fabrication technology of RF resonators, applicable in particle accelerators, developed on the base of TESLA (TeV Energy Superconducting Linear Accelerator) design, requires high purity niobium. The purity of $\mathrm{Nb}$ should be kept not only during fabrication of $\mathrm{Nb}$ sheets, but also during cavity fabrication and treatment. Niobium equally with its merits has and disadvantage - it is a good gas getter $(\mathrm{H}, \mathrm{O}, \mathrm{N})$, already at relatively low temperatures (when the protective $\mathrm{Nb}_{2} \mathrm{O}_{5}$ layer is removed).

Electron beam welding in ultra-high vacuum $\left(10^{-5} \div 10^{-8} \mathrm{mbar}\right)$ is applied in the standard fabrication of TESLA shape cavities. It was pointed out [1-5], that necessary parameters of the accelerating gradient in resonators $(30 \div 40$ $\mathrm{MV} / \mathrm{m}$ ) and high $\mathrm{Q}$ (quality factor) are reached when the low contents of gases in niobium are ensured. Earlier completed estimations [2], allow to consider acceptable by TTF (TESLA Test Facility) technology values of nitrogen and oxygen concentrations about $6 \div 10 \mathrm{wt}$. ppm and hydrogen $-3 \div 4$ wt. ppm. Gases, as interstitial impurities, have a significant influence on $\mathrm{Nb}$ 
properties. For example, several wt. ppm of hydrogen can be responsible for so called "hydrogen disease" of cavities.

For optimising the EB welding parameters, especially the vacuum condition, the residual gases contents in the niobium samples EB welded at ultra high vacuum $\left(10^{-5} \div 10^{-8} \mathrm{mbar}\right)$ were investigated. The measurement of hydrogen, oxygen and nitrogen contents in $\mathrm{Nb}$ was done by thermal desorption method.

\section{Experimental method.}

The niobium sheets with $R R R>350$ were taken for the investigations. The sheet welding was carried out on DESY equipment (EB Welding Machine) with the unique ultra-high vacuum chamber $\left(10^{-5} \div 10^{-8} \mathrm{mbar}\right)-$ Fig.1. During welding the electron beam of $2 \mathrm{~mm}$ in diameter followed the elliptical trajectory with the velocity along the seam of $8 \mathrm{~mm} / \mathrm{s}-$ Fig.2. The samples for analysis were taken in the form of niobium strips (length $50 \div 70$ $\mathrm{mm}$ ), cut from the EB welding area and heat affected zone - Fig.3. The sheets were welded under different pressures in the vacuum chamber (from $10^{-5}$ to $\left.10^{-8} \mathrm{mbar}\right)$.

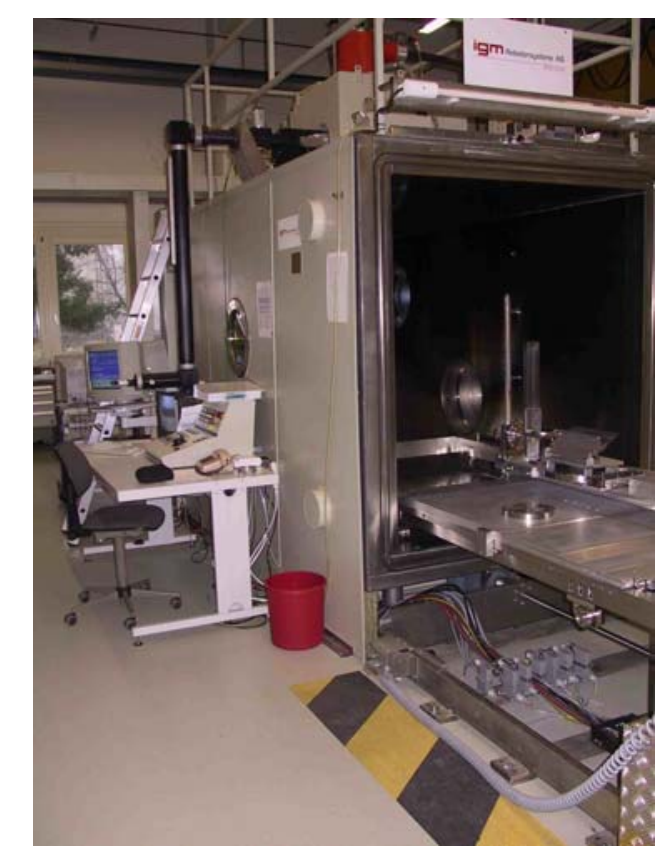

Fig.1 DESY Electron Beam Welding Machine 


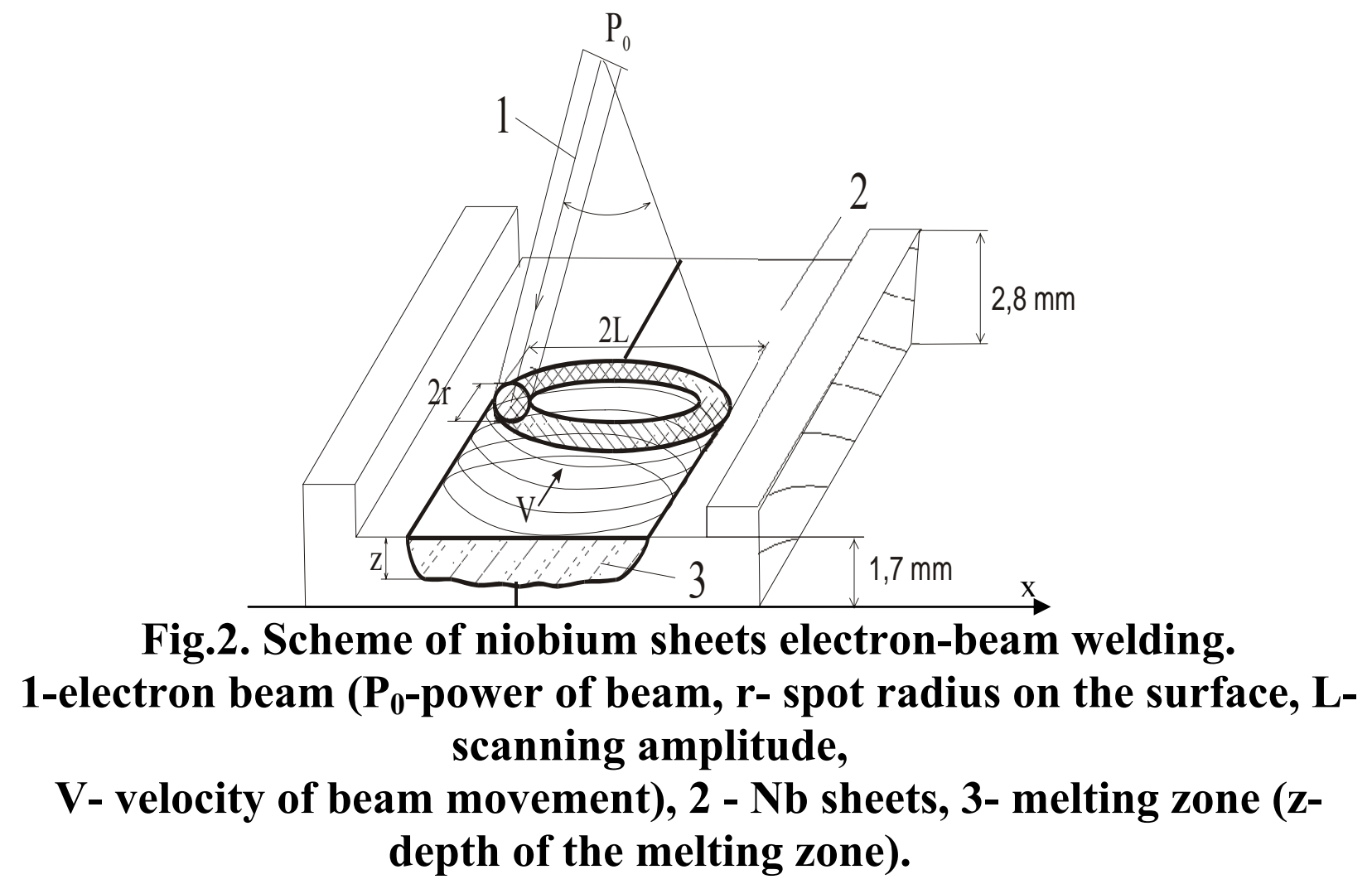

During the process of cavity welding in the seam area two zones are formed: zone of direct beam passing and zone of overlapping (in the area of beginning and the end of beam passing). These zones are differing by heat regime and may have different gas contents. Therefore, the cavity welding process was simulated in experiments, when electron beam had a direct and reverse passing. The length of one-direct passing was more than half of seam length, so in the middle of seam the zones with overlapping were formed (Fig. 3). Measurements were carried out also on the samples cut from area far away from the welded seam (reference - samples from non-affected zone). 

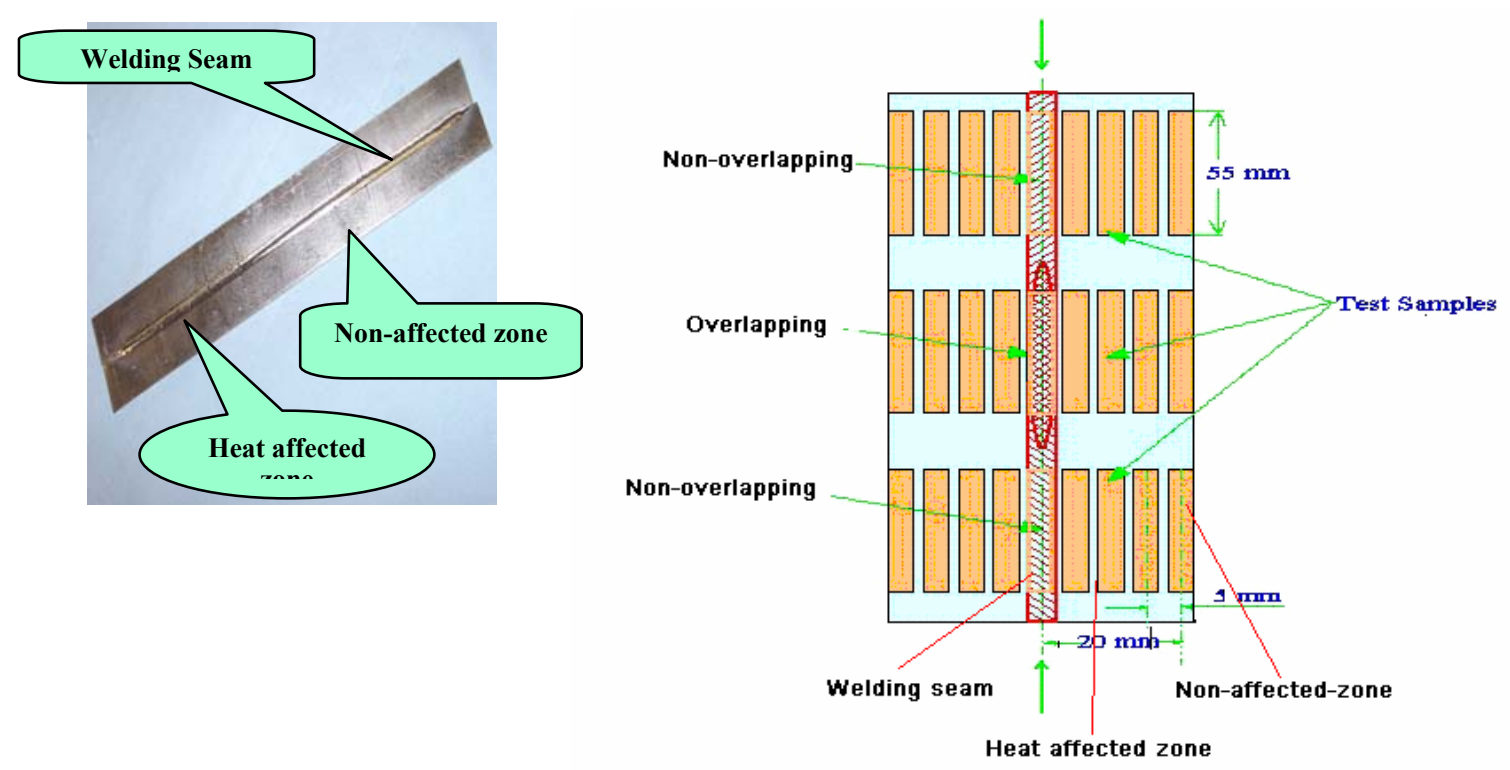

Fig.3. Niobium welding strip and scheme of samples cutting.

Measurements of the gases contents were done on gas analyzers of LECO company by hot extraction procedure. The hydrogen analysis was executed on RH-404 analyzer with tin flux pellets, using method of thermal conduction measurement. Masses of the samples $(0.5 \div 1.0 \mathrm{~g})$ were selected for exclusion of surface effects, appearing under small volume/surface ratio of the samples [6]. Nitrogen was defined by similar method on the TC-600 analyzer, with parallel measurement of oxygen contents in infrared measuring cell. Reduction of systematic inaccuracy of nitrogen content measurements was achieved, using platinum and nickel fluxes capsules. Masses of the samples $(0.05 \div 0.2 \mathrm{~g})$ for oxygen and nitrogen measurements were chosen during measurement procedure, using data of [6]. Optimal flux/sample relation were $5 \div 10$ for Pt and $1 \div 2$ for Ni fluxes. Calibration was done on the standard LECO $\left(\mathrm{H}_{2}\right)$ and Hereaus $\left(\mathrm{O}_{2}\right.$ and $\left.\mathrm{N}_{2}\right)$ samples. Measurements were done in each analyzing area on the samples series $(3 \div 5$ for hydrogen and $5 \div 6$ for oxygen and nitrogen). Total relative inaccuracy of measurements was $8 \div 10 \%(0.1 \div 0.3$ wt. ppm in absolute values $)$ for hydrogen and $15 \div 25 \%(0.5 \div 2 \mathrm{wt}$. ppm) for oxygen and nitrogen.

\section{Experimental results.}

Partial gas pressures in the vacuum chamber during EB welding of cavity and experimental niobium strips are shown in Fig.4 and Fig.5. 
Hydrogen pressure became few times higher during EB welding (tacking, $50 \%$ and full penetration welding of cavity (Fig.4, done by A. Brinkmann)). Similar hydrogen behavior can be seen in Fig.5. Low hydrogen pressure in the EB vacuum chamber (at the total pressure less than $10^{-4} \mathrm{mbar}$ ) allow to speculate about prevalence of the hydrogen desorption processes over absorption (in the temperatures range from 600 to $2000 \mathrm{~K}$ ). One more reason may be the water molecules decomposition, caused by electron beam [7]. Oxygen kinetics is more complicated (oxygen partial pressure goes down with the beginning of welding). Oxygen diffusivity is much less than hydrogen and oxygen desorption may occur predominantly in the form of volatile oxides $\mathrm{NbO}$ and $\mathrm{NbO}_{2}$ or in the form of $\mathrm{H}_{2} \mathrm{O}, \mathrm{CO}$ and $\mathrm{CO}_{2}$ (by way of combination with molecular O). Partial pressure of $\mathrm{CO}_{2}$ rises, when water pressure decrease (Fig.4) or stay constant (Fig.5). Probably, oxygen uptake by $\mathrm{Nb}$ takes place too. The kinetics of these processes may by slightly different at various pressures and usually is nonequilibrium over the small time of heating. Some difference between initial gas contents in cavity (after baking) and in experimental samples can be taken into consideration too. Also we see small nitrogen desorption, caused possible by nitrogen smaller diffusivity. So, we have predominant redistribution of nitrogen and oxygen in $\mathrm{Nb}$ during EB welding.

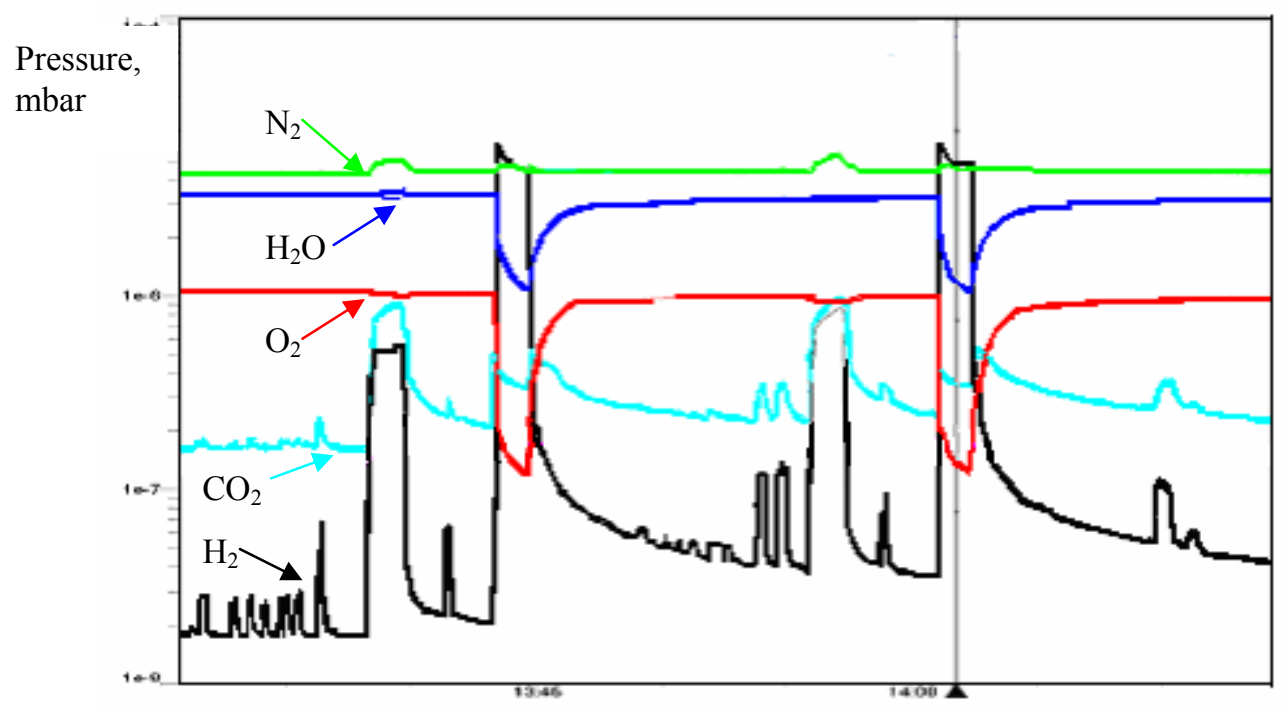

Fig.4. Temporal changes of gas partial pressure (mbar) in the vacuum chamber during the $\mathbf{E B}$ cavity welding. 


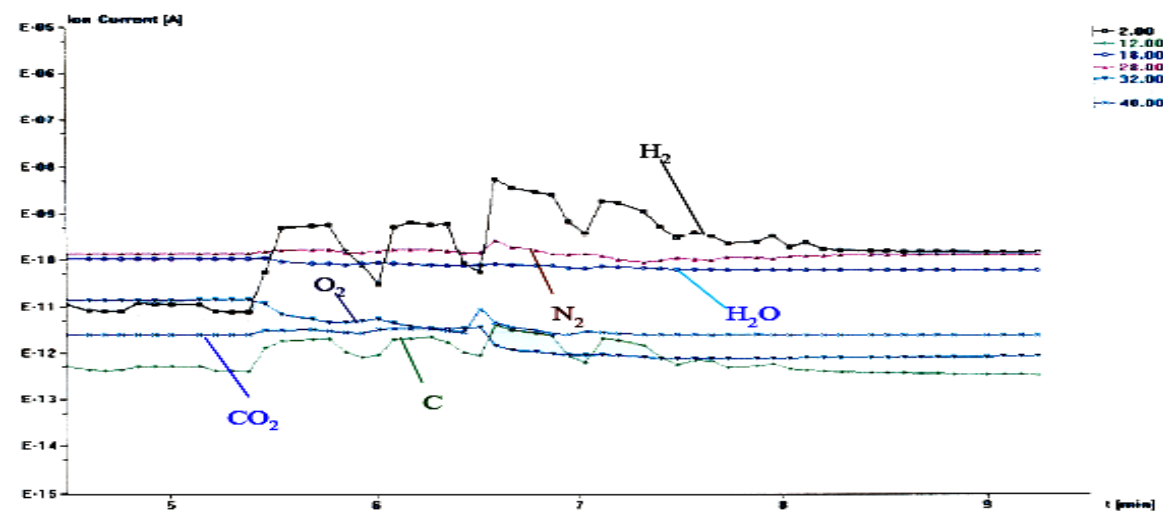

\section{Fig.5. Temporal changes of gas partial pressure in the vacuum chamber during the EB welding of experimental niobium sheets.}

Fig. $6 \div 11$ show the gases $\left(\mathrm{H}_{2}, \mathrm{O}_{2}, \mathrm{~N}_{2}\right)$ contents measurements results in the samples cut from non-overlapping and overlapping areas of EB welding. All the curves show:

1) Distribution of the remaining gases contents in the analyzing zone is heterogeneous. The reasons are the temperature regime and geometric profile of heat influence area (see discussions).

2) The width of gases redistribution area is greatly broader than only the area of melting and includes the EB heat influence zone too.

Hydrogen contents measurements in the areas without overlapping at different pressures are represented on Fig. 6.

It can be seen, that hydrogen contents at the pressures less than $1 \cdot 10^{-6}$ mbar does not exceed the technological requirements $(1 \div 3 \mathrm{wt}$. ppm for TTF). Gas distribution at the pressure higher than $1 \cdot 10^{-6}$ mbar is heterogeneous with high values of concentration peaks (up to $5 \div 7 \mathrm{wt}$. ppm). Such high values can cause the "hydrogen diseases" effect in the resonator. Similar character of hydrogen distribution we see in the zone of overlapping (Fig.7). 
Hydrogen (non-overlapping samples)

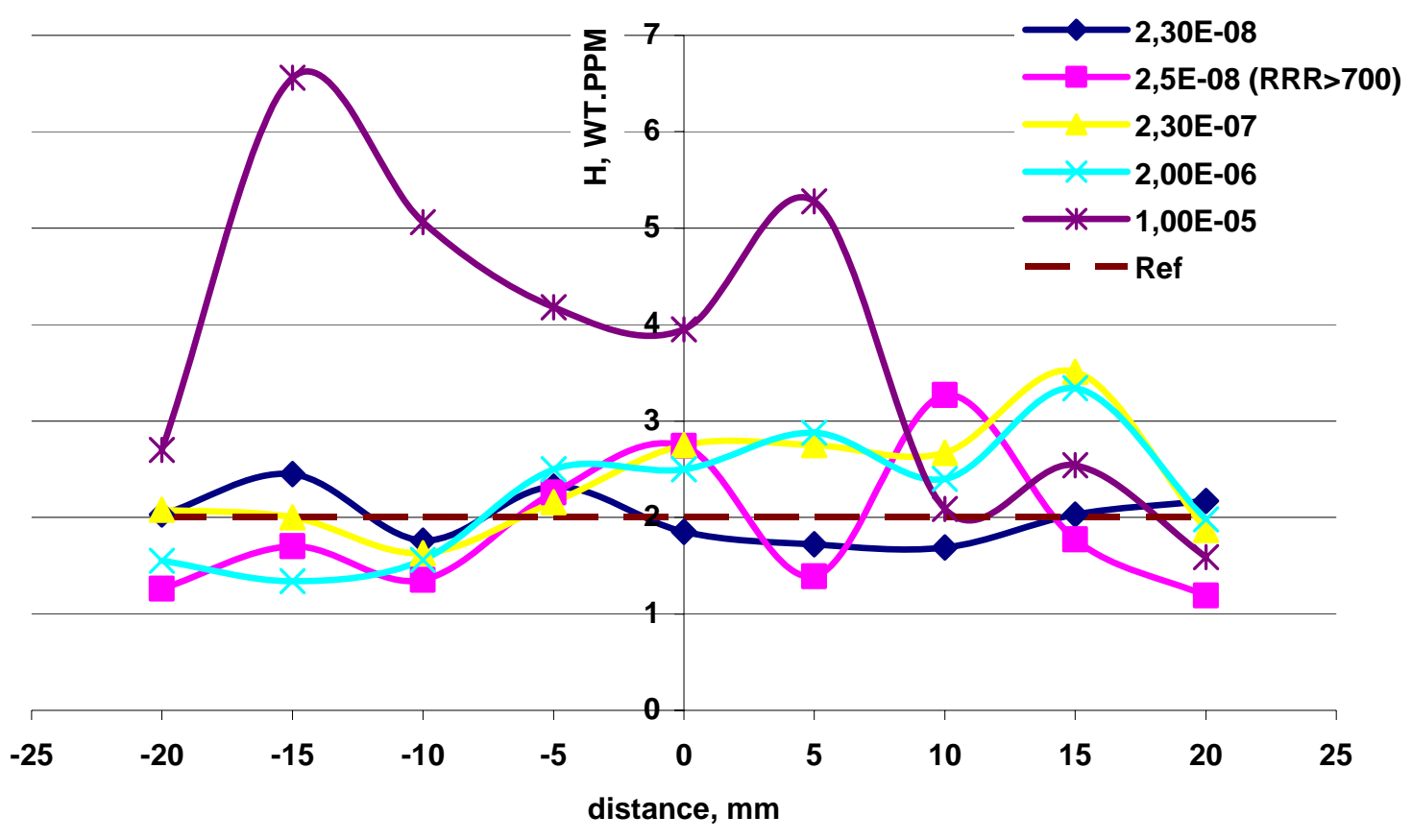

Fig. 6. Hydrogen contents in the non-overlapping zone at different pressures (mbar) in the welding chamber.

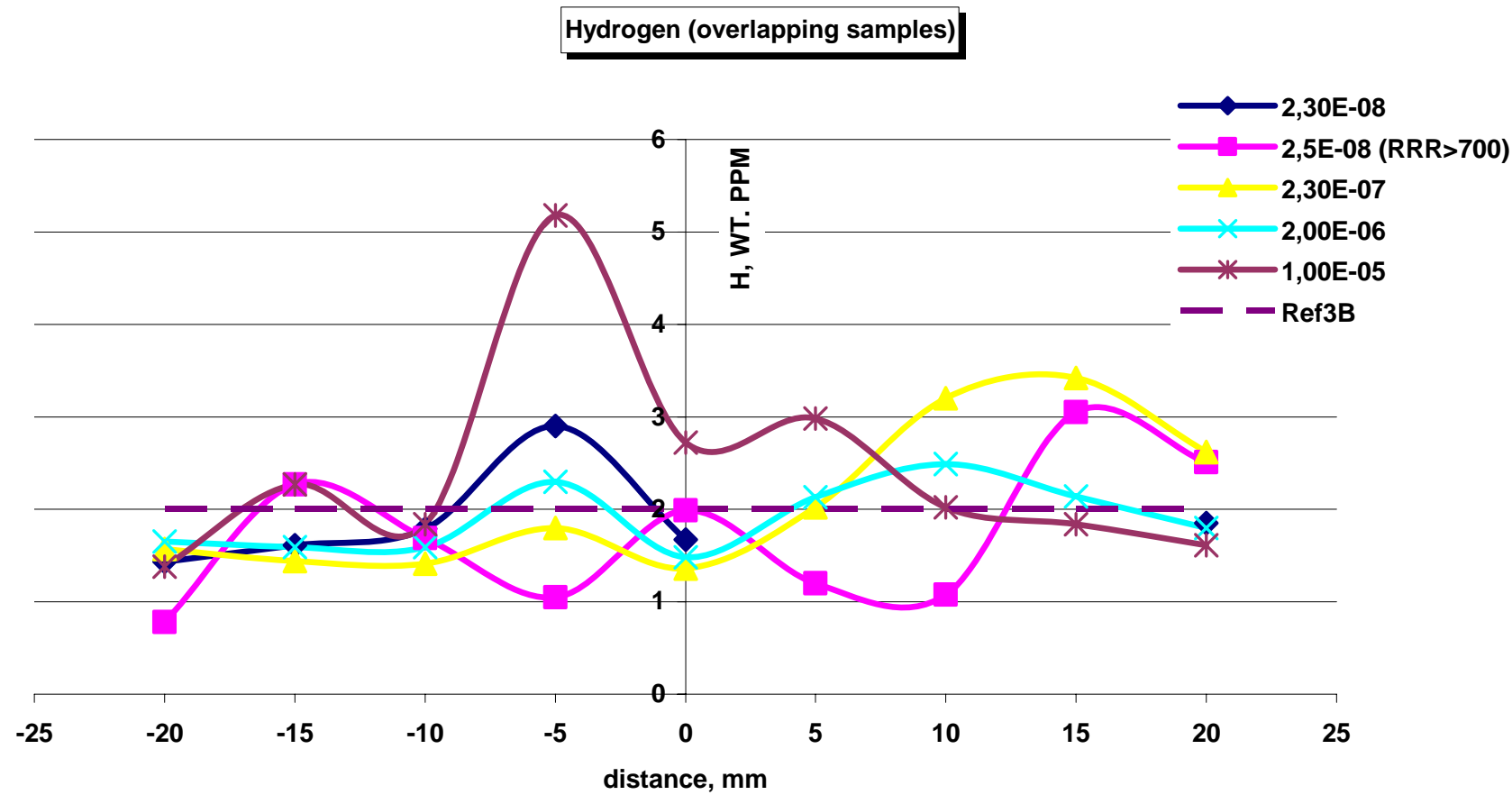

Fig. 7. Hydrogen contents in the zone of overlapping under different pressures (mbar) in the welding chamber. 
Nitrogen distributions in the welding area at different pressures are illustrated on Fig. 8 (zones without overlapping) and Fig. 9 (overlapping zones). Data, represented on this graph, show acceptable values of nitrogen contents (less than 8 wt. ppm) in complete range of considered pressures. The overlapping zones (Fig. 9) show increased variations of nitrogen concentration with maximal values on the borders between welding seam and heat affected zone. Measurements, executed at pressure $2.5 \cdot 10^{-8} \mathrm{mbar}$ for samples with high values of RRR - 700 $\div 750$ units show very low contents of nitrogen $(1 \div 2 \mathrm{wt}$. ppm). These samples are of high purity niobium of GIREDMET (Russia), produced by special refining method [8], using electrolysis.

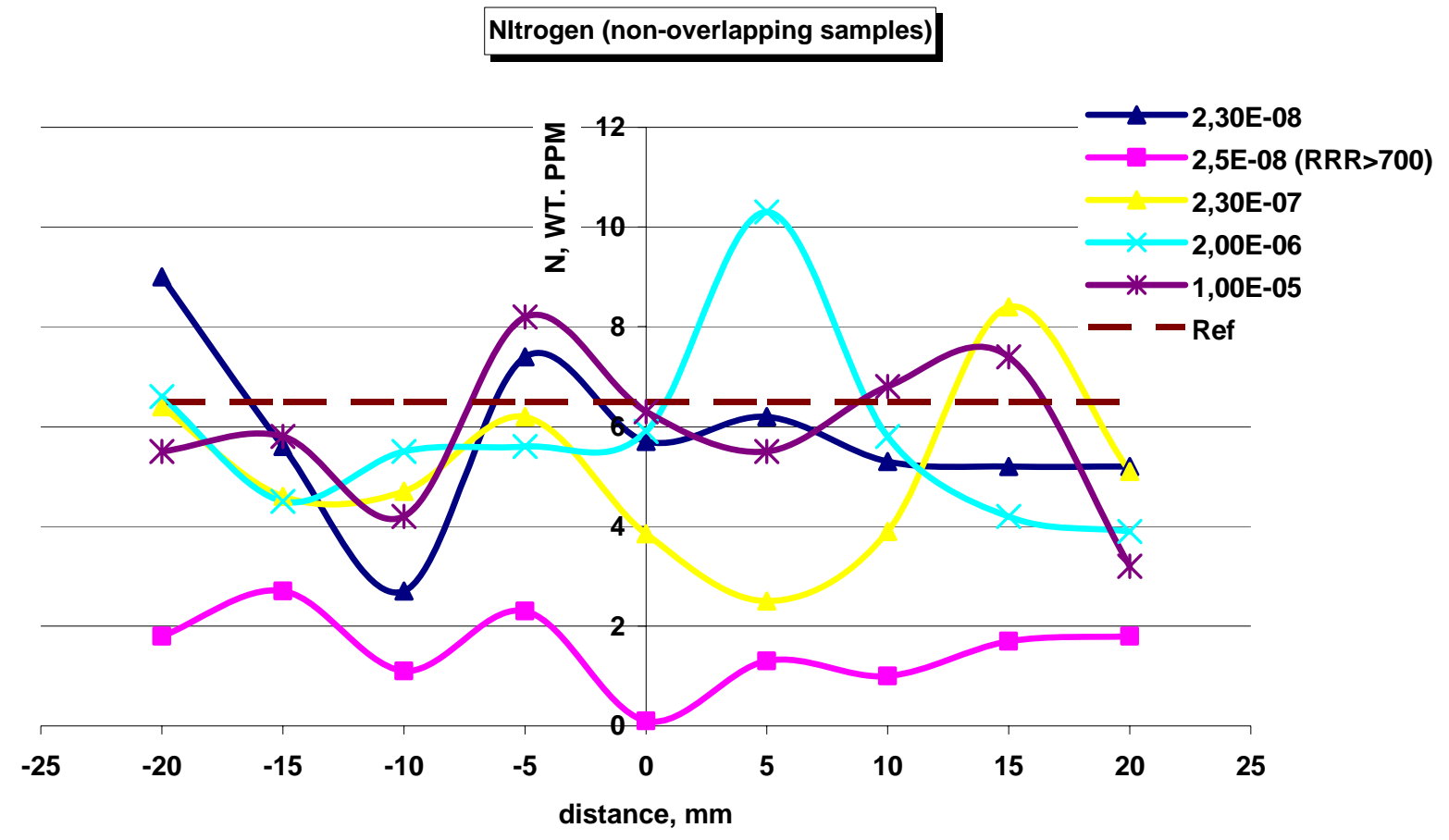

Fig. 8. Nitrogen contents in the non-overlapping zone under different pressures (mbar) in the welding chamber. 


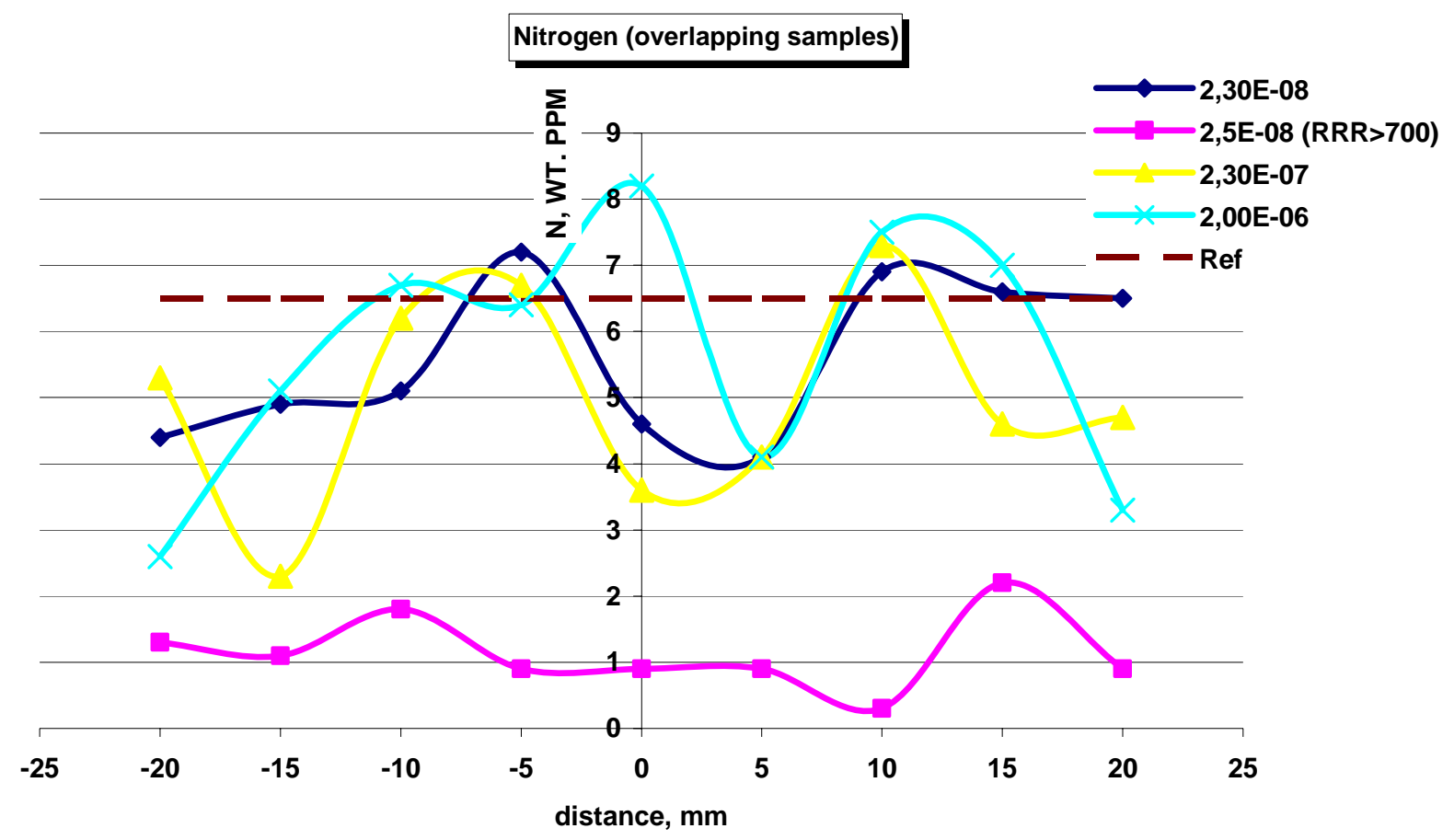

Fig. 9. The nitrogen contents in the overlapping zone under different pressures in the welding chamber.

The oxygen distribution is shown on Fig. 10 and 11. Oxygen contents value keeps within $5 \div 10$ wt. ppm for niobium samples with RRR within $300 \div 350$ (all curves, except $\mathrm{P}=2.5 \cdot 10^{-8} \mathrm{mbar}$ ). Enhanced values $(10 \div 18 \mathrm{wt}$. $\mathrm{ppm})$ have been observed at welding with low vacuum conditions $\left(1 \cdot 10^{-5}\right.$ mbar) and for samples with high RRR $\left(700 \div 750\right.$ units under $\mathrm{P}=2.5 \cdot 10^{-8}$ mbar). It is significant to note, smaller (in contrast to nitrogen) oscillation of oxygen concentration in the zones with overlapping. 


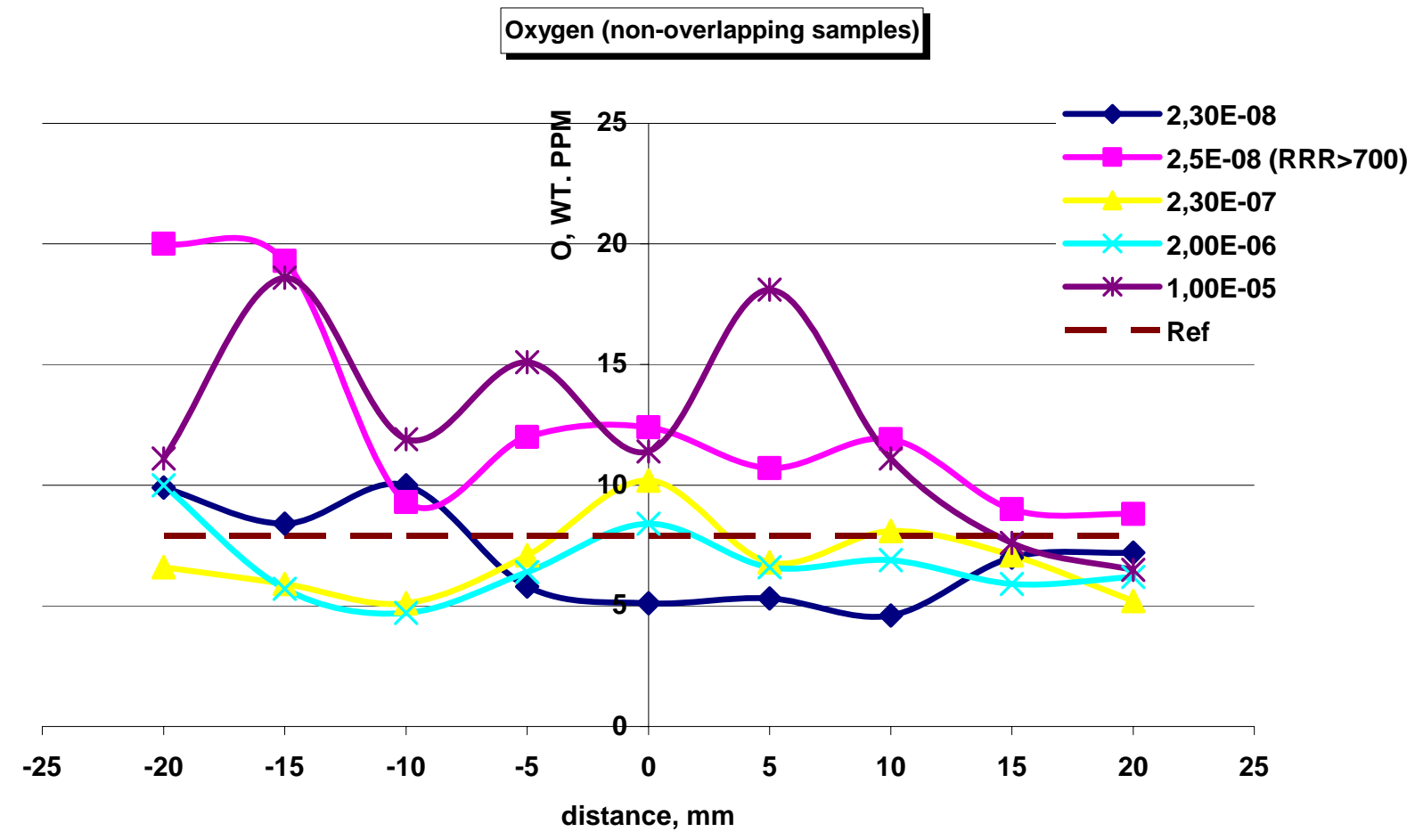

Fig. 10. The oxygen contents in the zone without overlapping under different pressures (mbar) in the welding chamber.

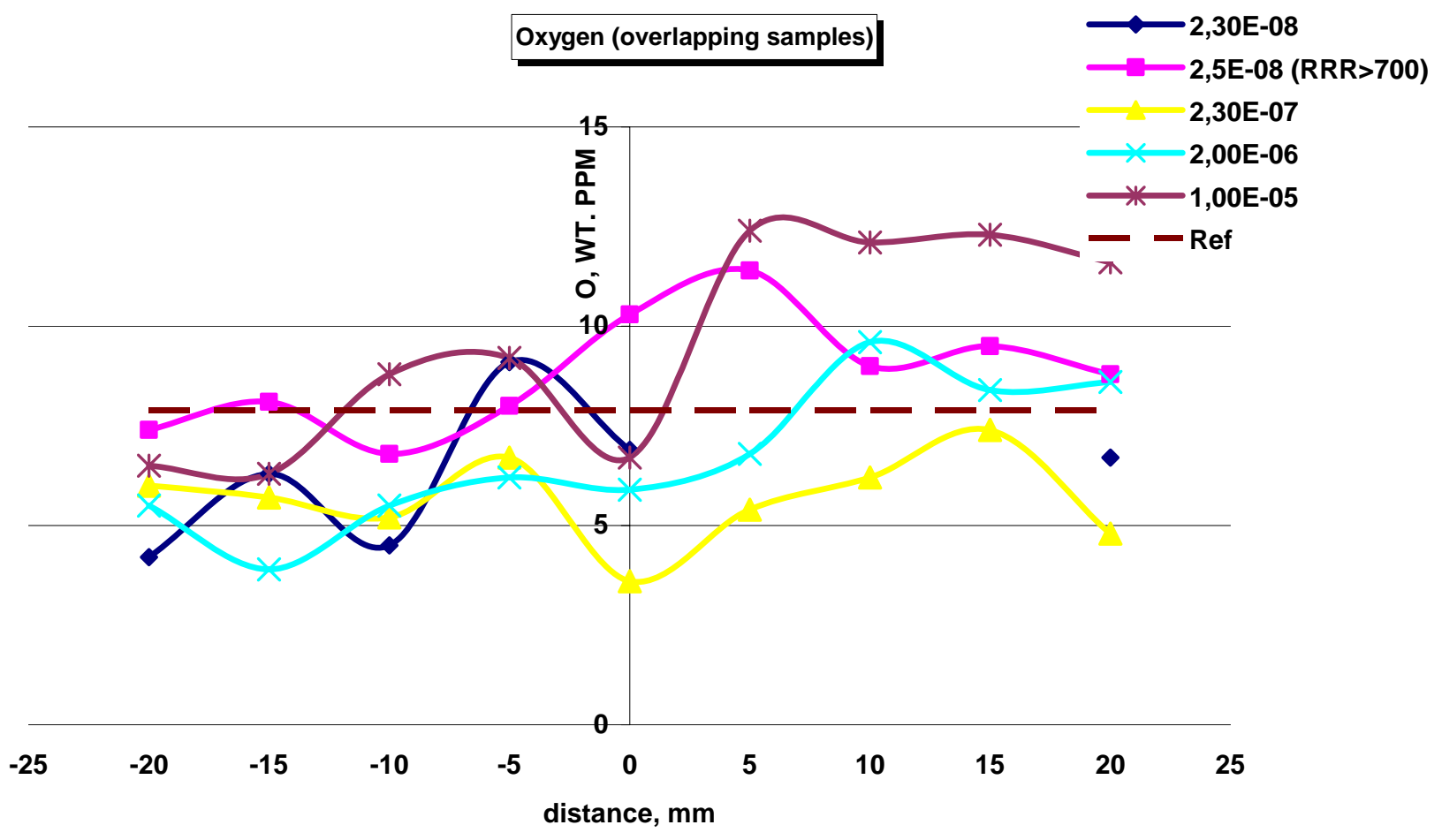

Fig. 11. The oxygen contents in the overlapping zone under different pressures (mbar) in the welding chamber. 
Influence of pressure on RRR was studied in [7]. It was pointed out, that vacuum better than $5 \cdot 10^{-6}$ mbar can slightly improve RRR in welding seam from 355 up to 370 , while the vacuum, better than $10^{-7}$ mbar, doesn't make additional contribution in RRR improvement. Our results demonstrate correlation between RRR and residual gas content at least for samples with $\mathrm{RRR}>350$.

\section{Discussion.}

\section{1) Unequal contribution of gases on RRR.}

It was pointed out in [6], that contribution of different defects in the scattering mechanism in niobium is not equal (nitrogen impurities effect proximally five times more and oxygen by a factor of 4.5 more than hydrogen). It results in rather small gas contents for niobium with RRR $>300$ (6-8 wt. ppm for any gas contents) and is in agreement with presented experiments. $\mathrm{Nb}$ with ultra-high RRR values $(700 \div 800)$ must have ultra low gas contents (estimation, done in [2] predict values less than 2 wt. ppm both oxygen and nitrogen). Our experiments show high values of oxygen $(8 \div 12$ wt. ppm) with a very low $(1 \div 2$ wt. ppm) nitrogen and hydrogen contents. Statistic of data show (see, for example, Fig. 12) high values of correlation coefficient between average values of gas content and RRR for nitrogen ( $|\mathrm{r}|=0,85$ for non-overlapping samples and $|\mathrm{r}|=0,96$ for overlapping samples) and considerable smaller correlation for hydrogen and oxygen $(|\mathrm{r}| \sim 0,4 \div 0,5)$. It is possible, that in the second case we must take into account all the other scattering mechanisms (defects, caused by metal impurities and carbon), considering that impurity contents may be in electrolytic niobium qualitative different. 


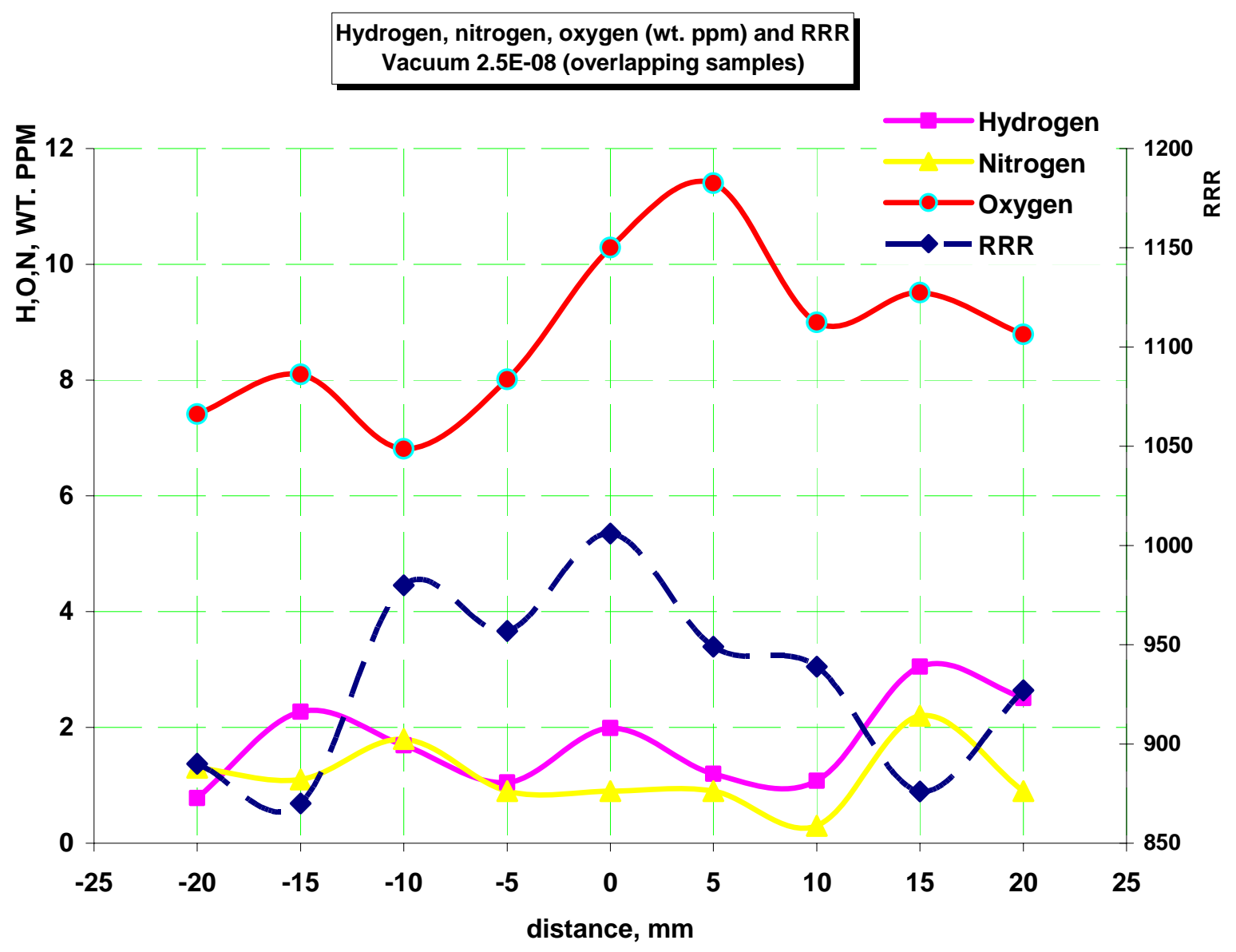

Fig.12. Comparison of gases distribution (wt. ppm) and RRR. Niobium with high RRR, welding at the pressure of $2.5 \cdot 10^{-8} \mathrm{mbar}$. Samples from zone with overlapping.

\section{2) Heterogeneity distribution of gases by width of heat influence zone. \\ The observed feature of gases contents behavior is the heterogeneity of their distribution by in the welded seam and thermally influenced areas. Calculation of the gases redistribution during the welding by EB, moving by direct and elliptical combined trajectory (scanning), is a complicated task. Some rough estimation can be done if we'll take into account the activation temperature influence on the gas diffusion in metal. It allows us to note the correlations of the temperature in the warm-up area and the residual gases distribution. In a majority cases it is possible to confine oneself by diffusion kinetics description, neglecting surface effects, and ignore temperature and concentration dependence of diffusion and thermal constant in niobium. Also}


we may reject pressure influence on hydrogen permeability in niobium, since our pressures are lower than $10^{-2}$ mbar [9].

The analytical solving of multivariate heat conductivity equation for our edge conditions is complicated. But there are many solutions in the theory of heat conduction, simulating the problem of scanning heat influence on the surface of material. For example, equation, proposed in [10], allows calculate temperature in the scanning zone (Fig.2):

$$
T(x, y, t)=\varphi \int_{0}^{t} \frac{q \cdot d t^{\prime}}{8 \pi \lambda \delta\left(t-t^{\prime}+t_{0}\right)}\left\{\exp \left[-\frac{\left(x-v t^{\prime}\right)^{2}+(y+L)^{2}}{4 a\left(t-t^{\prime}+t_{0}\right)}\right]+\exp \left[-\frac{\left(x-v t^{\prime}\right)^{2}+(y-L)^{2}}{4 a\left(t-t^{\prime}+t_{0}\right)}\right]\right\},
$$

were L - amplitude of oscillation; $\delta$-material thickness; $\mathrm{v}$ and $\mathrm{q}-$ velocity and surface power of the heat source; a and $\lambda$ - thermal diffusivity and thermal-conductivity coefficients; $\varphi$ - equalizing coefficient for impulse source. Calculations show regular temperature inequality by the width of the scanning zone and asymmetry, depending of oscillation amplitude. Disadvantage of this simulation is absence of frequency dependence and necessity of $\varphi$ and $\mathrm{L}$ fitting to take into account the kind of scanning beam movement.

Heat-transfer equations, proposed by author [11], give on opportunity to calculate temperatures, depending of scanning frequency and kind of the heat source movement on the surface. For example, equation for the case, when $\mathrm{L}>\mathrm{d}(\mathrm{d}$ - diameter of heat spot on the surface), for zone with coordinates $(\mathrm{L}-\mathrm{d})<\mathrm{IxI} \leq \mathrm{L}$ is:

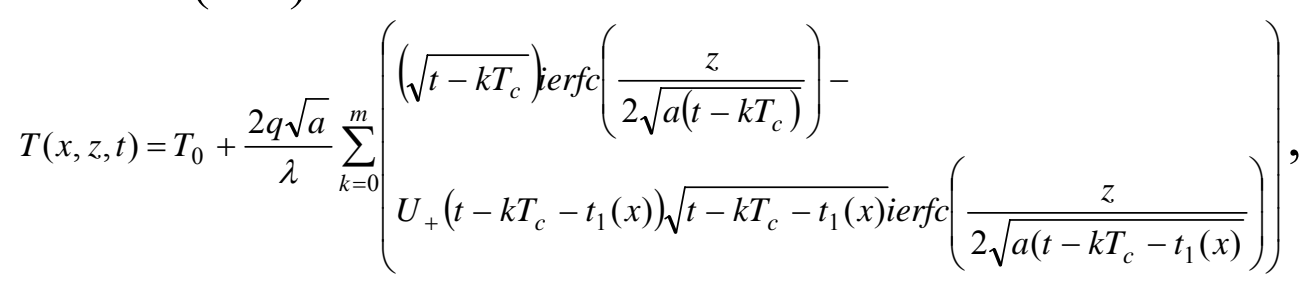

where $T_{c}$ - period of oscillation, $t_{1}(x)$ - time of heat influence during period in the chosen point, $\mathrm{T}_{0}$ - initial temperature, $\mathrm{m}$ - number of cycles to moment $t, U_{+}(\varphi)$ is 0 or 1 , if $\varphi \leq 0$ or $\varphi>0$. Imperfection of this equation is in the limitation on the velocity of heat source and sample thickness and difficulties with temperatures consideration far from the scanning zone.

Nevertheless, both simulations show (Fig.13) that under scanning heat treatment of niobium $\left(\mathrm{a}=2 \cdot 10^{-6} \mathrm{~m}^{2} / \mathrm{s}\right.$ and $\lambda=65 \mathrm{~W} /(\mathrm{m} \cdot \mathrm{K})$ - average values 
close to the melting point) the width and depth of temperature distribution is heterogeneous in the area of beam movement. Heat influenced zone (where the temperature is higher than $\mathrm{Nb}_{2} \mathrm{O}_{5}$ critical temperature) is about $10 \div 15$ $\mathrm{mm}$ (Fig. 14). Also distinction of maximal temperatures and time of these temperatures achievement in different areas is represented (Fig. 15).

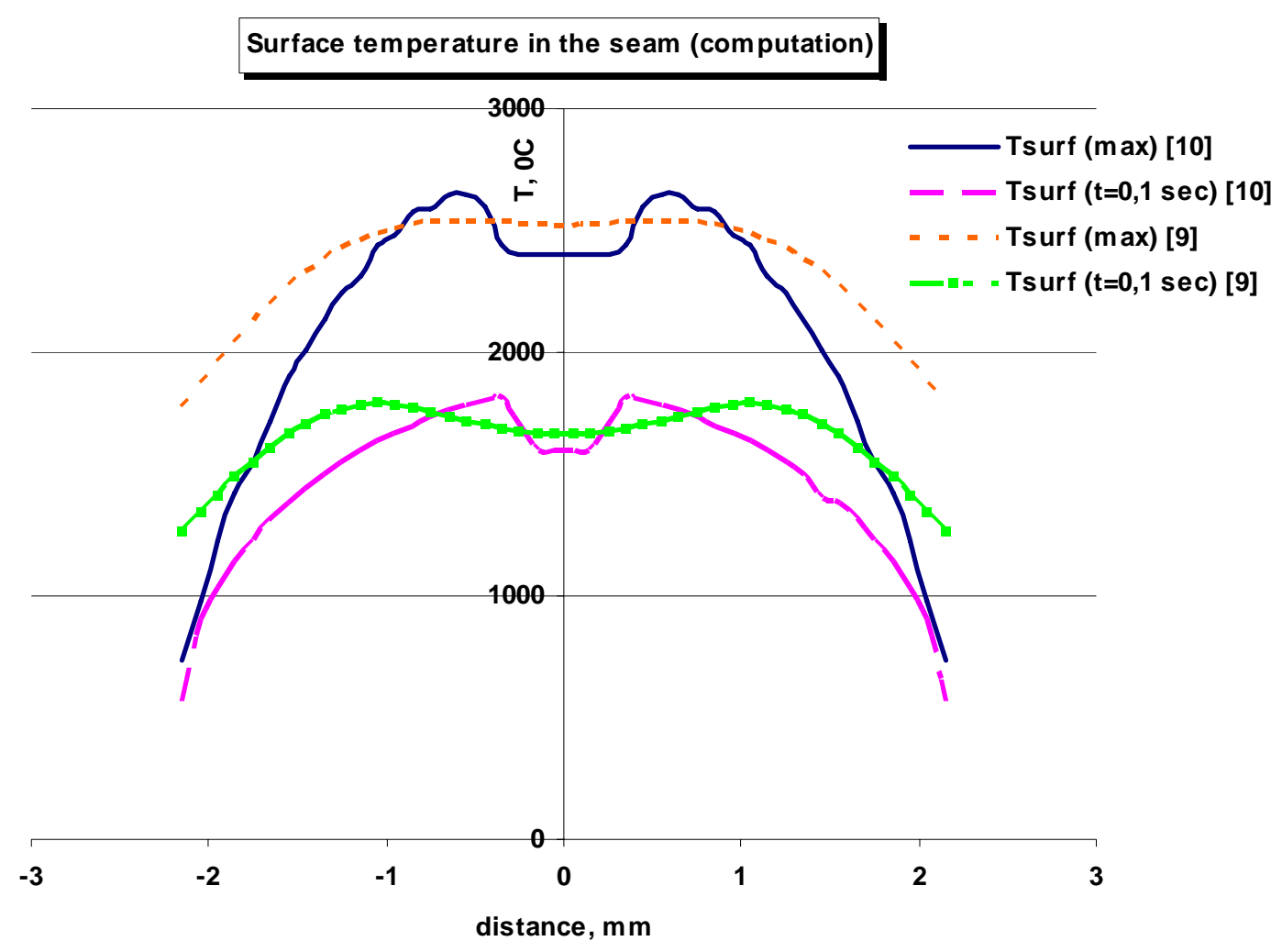

Fig. 13. Surface temperature distribution by the width of the seam (computation by equations (1) and (2)).

$\left(L=2,25 \mathrm{~mm}, d=2 \mathrm{~mm}, V=8 \mathrm{~mm} / \mathrm{s}, T_{c}=10^{-3} \mathrm{~s}, \mathrm{q}=2 \cdot 10^{4} \mathrm{~W} / \mathrm{sm}^{2}\right)$. 


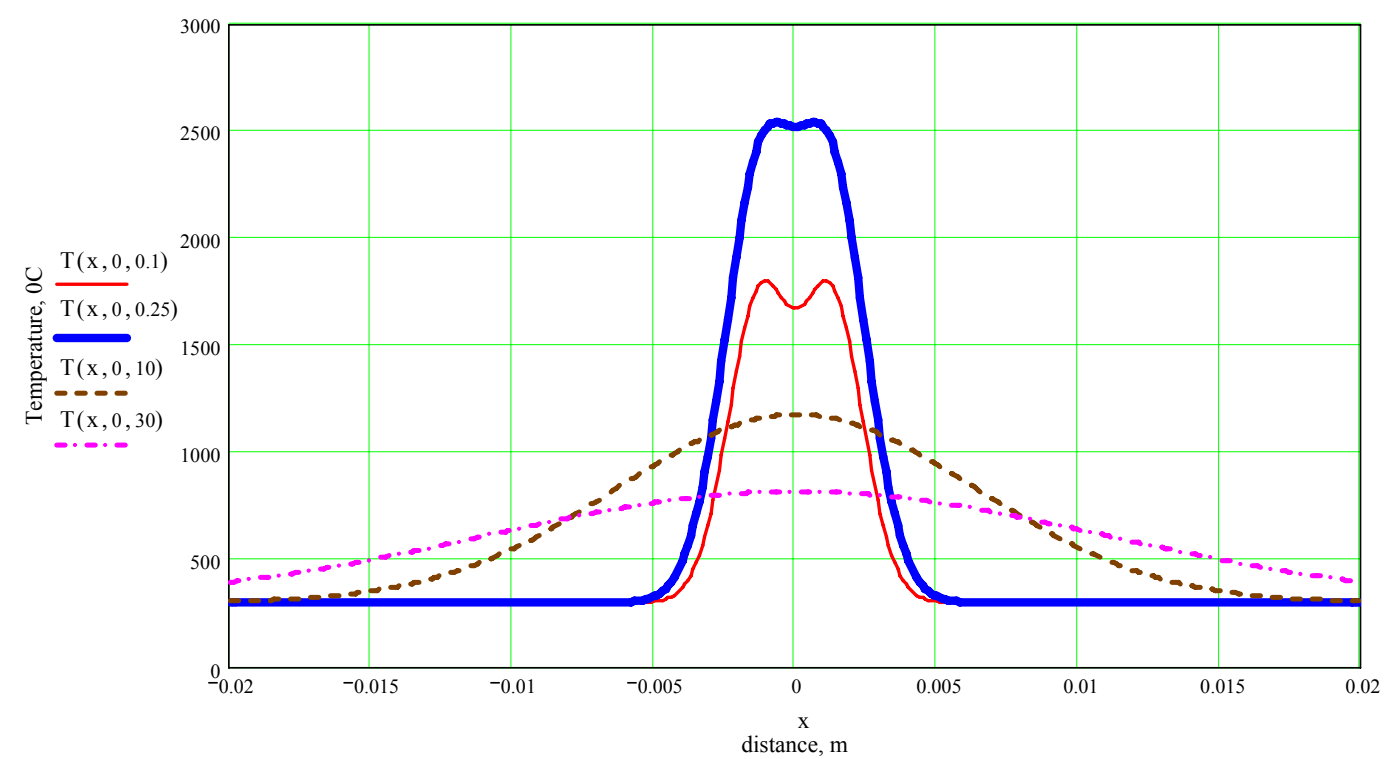

Fig. 14. Temperature $T(x, z, t)$ distribution by the width of heat influence zone

(computation of (1)). $[t]$ - sec.

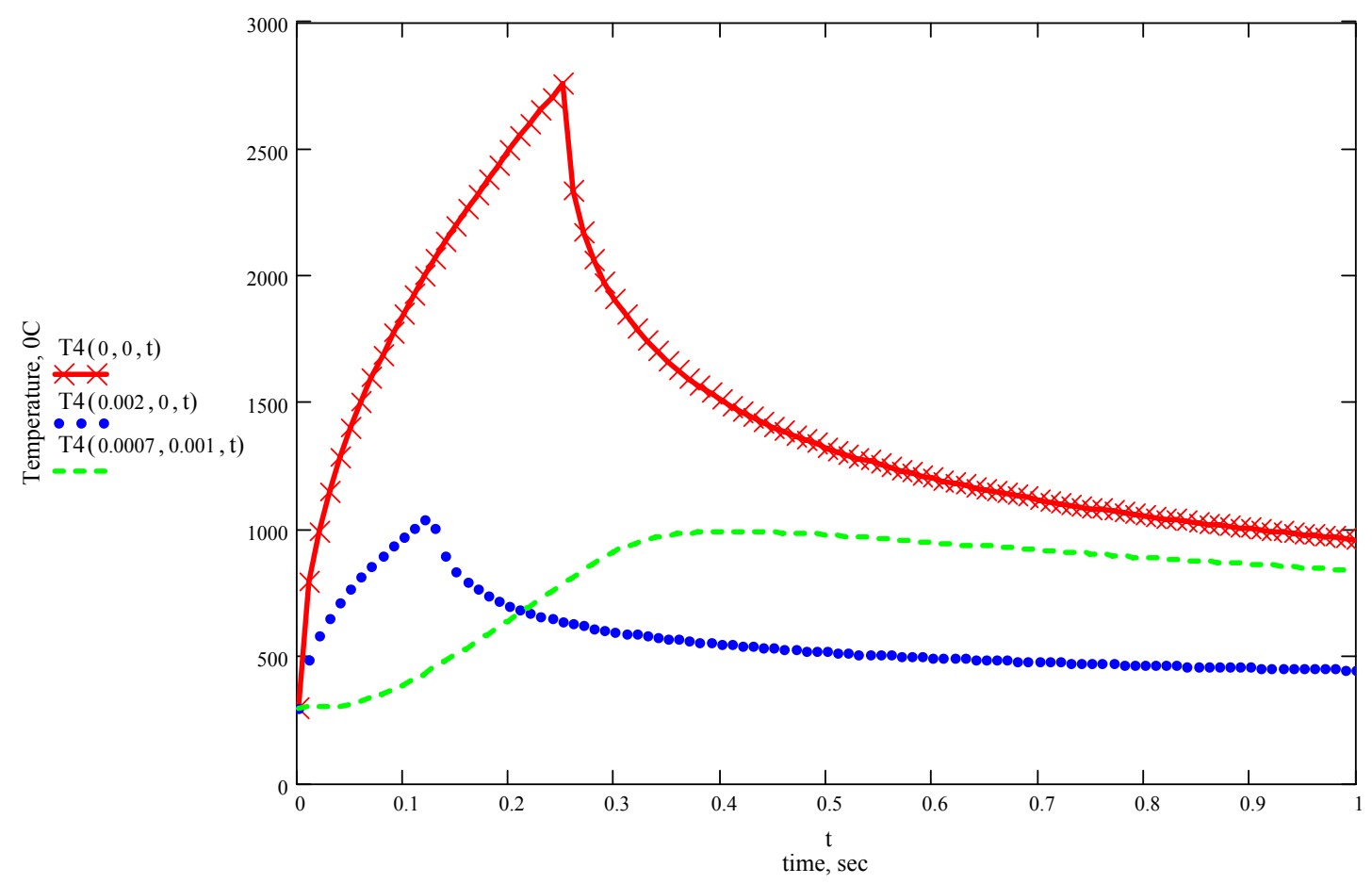

Fig. 15. Time-temperature $(T(x, z, t))$ dependence in the seam and heat influenced zone (computation of $(2)) .[x[,[z]-m$.

In the heat influence zone the following kinetic processes can take place: sorption-desorption on the internal and external surface of niobium sheet, as 
well as diffusion redistribution of residual gases in the sample (carrying the gases to surfaces and in the plate plane). Under very low pressures in vacuum chamber $\left(\mathrm{P}<10^{-6}\right.$ mbar $)$ it is possible to neglect the thermally nonequilibrium processes of gases adsorption on the surface (the equilibrium concentrations $\mathrm{C}_{\mathrm{eq}} \sim P^{0.5}$ in analyzing range of pressures negligible values) and consider only diffusion processes in the volume with desorption of gases on the both surfaces (time of hydrogen diffusion $\tau_{\mathrm{D}} \sim \mathrm{Z}^{2} / \mathrm{D} \sim 0,1 \mathrm{~s}$ is comparable with the heat influence time on the surface $\tau \sim 0,1 \div 0,4 \mathrm{~s}$ ). Timetemperature dependences (Fig.15) allow estimating the diffusion length of gases in heat influence zone. It averages $0.3 \div 0.5 \mathrm{~mm}$ for $\mathrm{H} 2 ; 0.02 \div 0.06 \mathrm{~mm}$ $(\mathrm{O} 2)$ and $0.01 \div 0.04 \mathrm{~mm}(\mathrm{~N} 2)$, decreasing by depth. Regarding the probable heterogeneity of gas distribution by depth, we may assume that residual gases can diffuse not to the surface only, but in the plate plane too and redistribute themselves in the process of temperature relaxation. At the same time hydrogen desorption is the predominant process, causing its smaller concentration oscillations after welding. The reason of smaller oscillations of oxygen concentrations may be in greater diffusivity of oxygen atoms and, agreeably, smaller times of concentration peaks relaxation (for the equal time of heat influence). The great importance have also the effects of residual gases concentration nearby the borders of welded seam, caused by sharp temperature drop in the area of niobium plate thickening (from 1,7 to 2,8 $\mathrm{mm}$ - refer to Fig.2).

Thereby, the condition for redistribution of remaining gases is forming in the thermal influence zone. When pressure is above $(1 \div 5) \cdot 10-6$ mbar, gases sorption from chamber increases, producing enlarged values of residual gases contents both in the seam, and in the thermal affected zone (Fig. 16-17). 


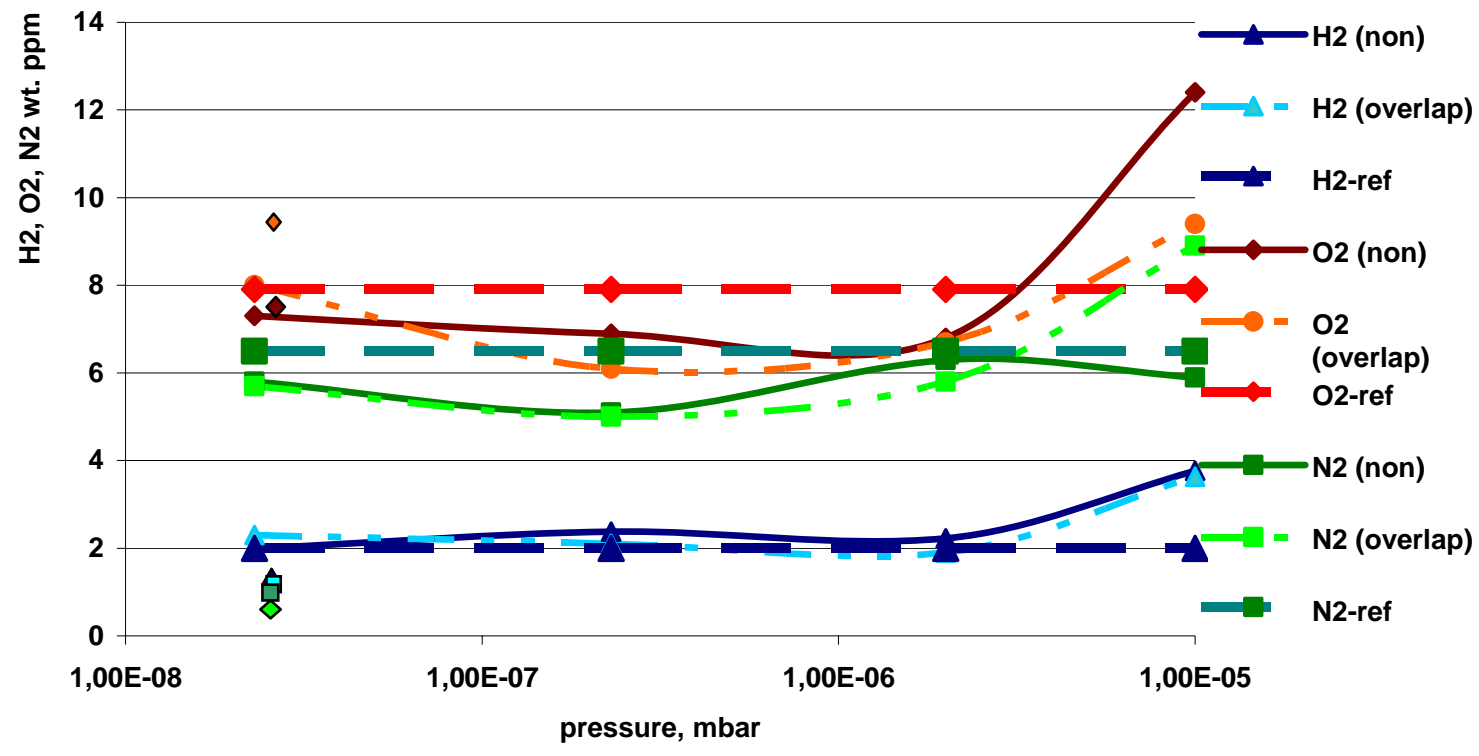

Fig. 16. Residual gases average concentrations in the heat influence zone (samples with non- and overlapping areas) versus pressure. Values for samples with $\mathbf{R R R}>\mathbf{7 0 0}$ are shown by points.

As shown, gas contents oscillations with pressure change are more expressive in the seam zone, where temperature activation is maximal. However, peak values are not critical in the pointed pressure range. Difference between residual gases contents in the zones with and without overlapping is more pronounced in the seam area, too. Nevertheless, this difference, in most cases, is in the frame of experimental inaccuracy. 

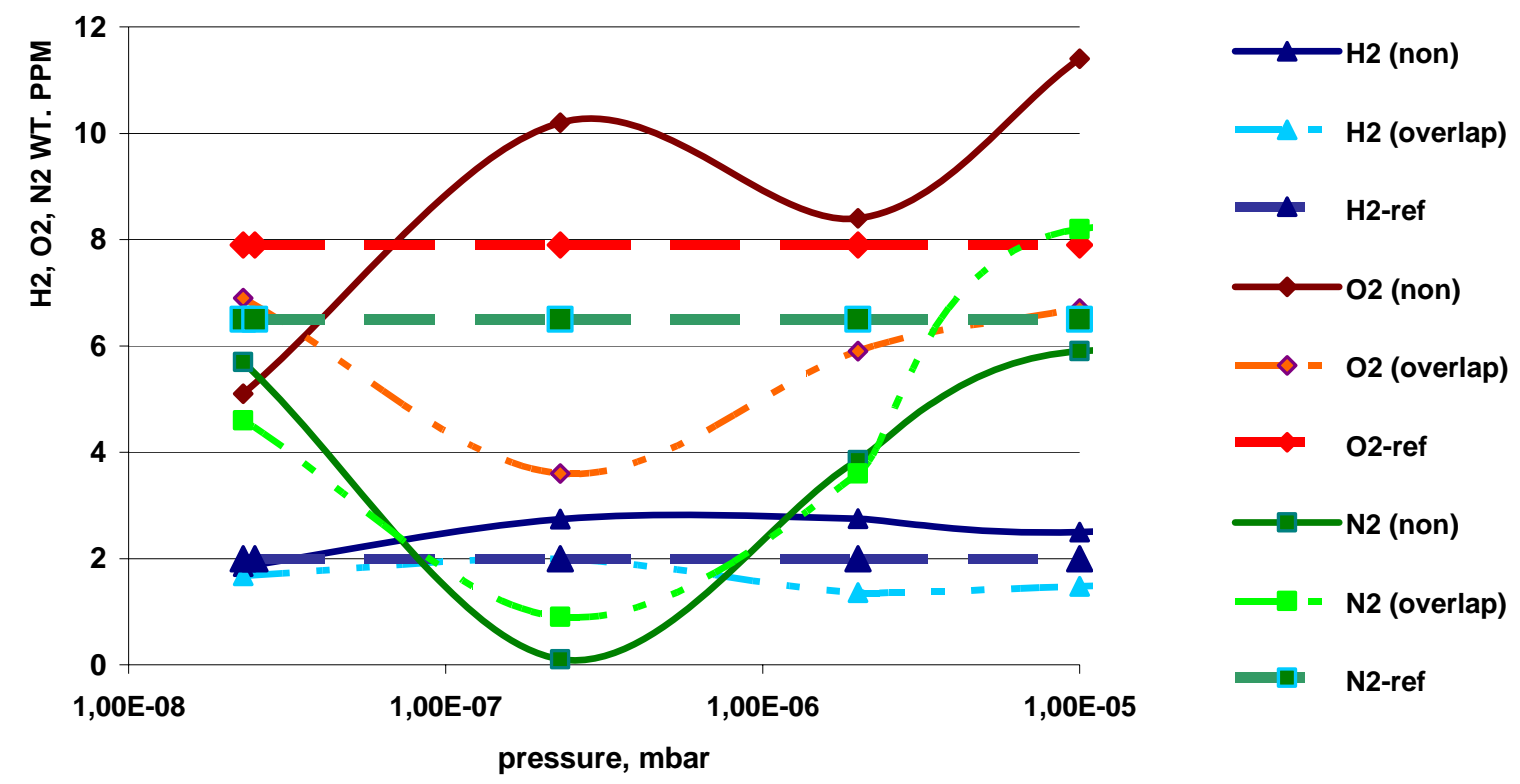

Fig.17. Average concentrations of residuals gases in the zone of welding seam (samples with non- and overlapping areas) versus pressure.

\section{Conclusions.}

1. $\mathrm{EB}$ welding technique provides for high purity $\mathrm{Nb}$ acceptable for TESLA- design contents of residual gases in the area of welded seam at vacuum of $10^{-6}$ mbar and below. Ultrahigh vacuum $\left(\sim 10^{-8} \mathrm{mbar}\right)$ is not necessary. In niobium strips with beam overlapping accumulate gases over acceptable values at the mentioned pressures range were not observed.

2. Particularity of electron beam movement and geometry profile of welding area leads to the heterogeneity of gases contents in the heat affected zone.

3. Correlation between of nitrogen and hydrogen of concentration oscillations and RRR values observed.

\section{References.}

1. Brinkmann A., Gossel A., Moller, W.-D., Pekeler, M., Proch, D., Proceedings of 8th Workshop on RF Superconductivity, October 6-10, 1997, 
Italy, pp.452-456 2. Singer, W., Proch, D., Proceedings of the 7th workshop on RF superconductivity, October 1995, Gif sur Yvtte, France, pp.547-550

3. Wen H.M., Singer W., Proch D., TESLA Report 98-02(1998), DESY, Hamburg, Germany, URL http://tesla.desy.de/ new_pages TESLA/TTFnot98.html

4. Myneni G. R., Agnew S., Ciovati G., Kneisel P., Lanford W. A., Paul R. L., and Ricker R. E.. Mechanical Properties of High Purity Niobium. Novel Measurements, September 8-12, 2003

5. Calatroni S., Barbero Soto E., Benvenuti C., Ferreira L., Neupert H., Progress of $\mathrm{Nb} / \mathrm{Cu}$ technology with $1.5 \mathrm{GHz}$ cavities, 11 th Workshop on RF Superconductivity SRF2003 - 10 Sept. 2003

6. Schulze K., Bach O., Lupton D., Schreiber F. Purification of Niobium, Niobium Proceedings of the International Symposium, San Francisco, California, November 8-11, pp. 163-224.

7. Singer W., Singer X., Tissen J., Wen H.M., Scholz F., RRR degradation and gas absorption in the electron beam welding area of high purity niobium. Hydrogen In Materials and Vacuum Systems, $1^{\text {st }}$ International Workshop 11-13 November 2002, AIP Conference Proceedings, Vol. 671, pp. 162-175.

8.Voronenko L.I., Eljutin A.V., Kovalev K.S. and Kovalev F.V., Verfahren zur Hochreinniobproduction. Patent C 22 B 34/24 (DE 101 12822 A 1), 11.10.2001.

9. Sokolovsky O.R., Fyodorov V.V., Sidorak I.I., Parheta R.G.. Measurement of hydrogen diffusion constant in niobium by electrical conduction method. The Interaction of hydrogen with metals. Sverdlovsk: The Ural's branch of USSR Scientific Academy, 1989 - p.136-137.

10. Bashkatov A.V., Postnikov V.S., Ryzhkov F.I. Thermal fields determination at unsteady electronic beam welding. - FiHOM, 1972, №2, p. 23-29.

11. Anakhov S.V., Alexeenko N.N., Pyckin Y.A., Fominych S.I. Method of warm-up fields calculation in the process of scan plasma case-hardening. - High Temperature (TVT), 1994, V. 32, №1, P.40-43. 